Outlook | Published: 12 September 2007

\title{
The road to recovery
}

Carlos M. Morel, José R. Carvalheiro, Carmen N. P. Romero, Eduardo A. Costa \& Paulo M. Buss

Nature 449, 180-182 (13 September 2007) | Download Citation

\section{Brazil urgently needs to improve infrastructure for generating pharmaceuticals to alleviate the plight of its poor and marginalized populations, say Carlos M. Morel et al.}

Despite Brazil's strength in basic scientific and medical research, a large proportion of the population still suffers from ill health. Diseases such as tuberculosis and leprosy are highly prevalent in poor populations, and about 46,000 people die each year from infectious diseases. What is going wrong?

As a 'middle-income' country, Brazil needs to cope with diseases and health problems that are prevalent worldwide, such as diabetes, hypertension and obesity. In addition, it has to deal with neglected diseases, such as malaria and leprosy, and some of the world's 'most-neglected' diseases, such as dengue fever, leishmaniasis and Chagas' disease. But few of the scientific discoveries made in Brazil lead to new drugs for these infectious diseases. This is driving the government into the red, with imported medical products costing billions of dollars each year. Moreover, any successes in healthrelated biotechnology $y^{1,2,3}$ are undermined by the poor delivery of health-care services across the country ${ }^{4}$ and by the consistently ineffective implementation of education and industrial policies.

Certainly, there has been no shortage of effort by Brazilian researchers. Since 1990, the number of articles published by researchers from Brazilian institutes has steadily increased (see graphic, below). Similarly, the number of Brazilian patent applications at the US Patent and Trademark Office has also increased during this period. But the ratio of patent applications to research papers is low, suggesting that not enough research is 
being translated into real products ${ }^{5}$.

The path from innovation to application in health systems and services has recently been proposed to involve six components ${ }^{6,7}$. These are carrying out research and development; manufacturing products to appropriate standards; promoting and sustaining domestic markets; promoting and sustaining export markets; creating and implementing systems for intellectual-property management; and designing and implementing systems for the regulation of drugs, vaccines, diagnostics and medical devices. This framework is a useful guide to help analyse the strengths and weaknesses of Brazil's innovation-application process and points to one key issue underlying all these areas in Brazil: a lack of effective infrastructure.

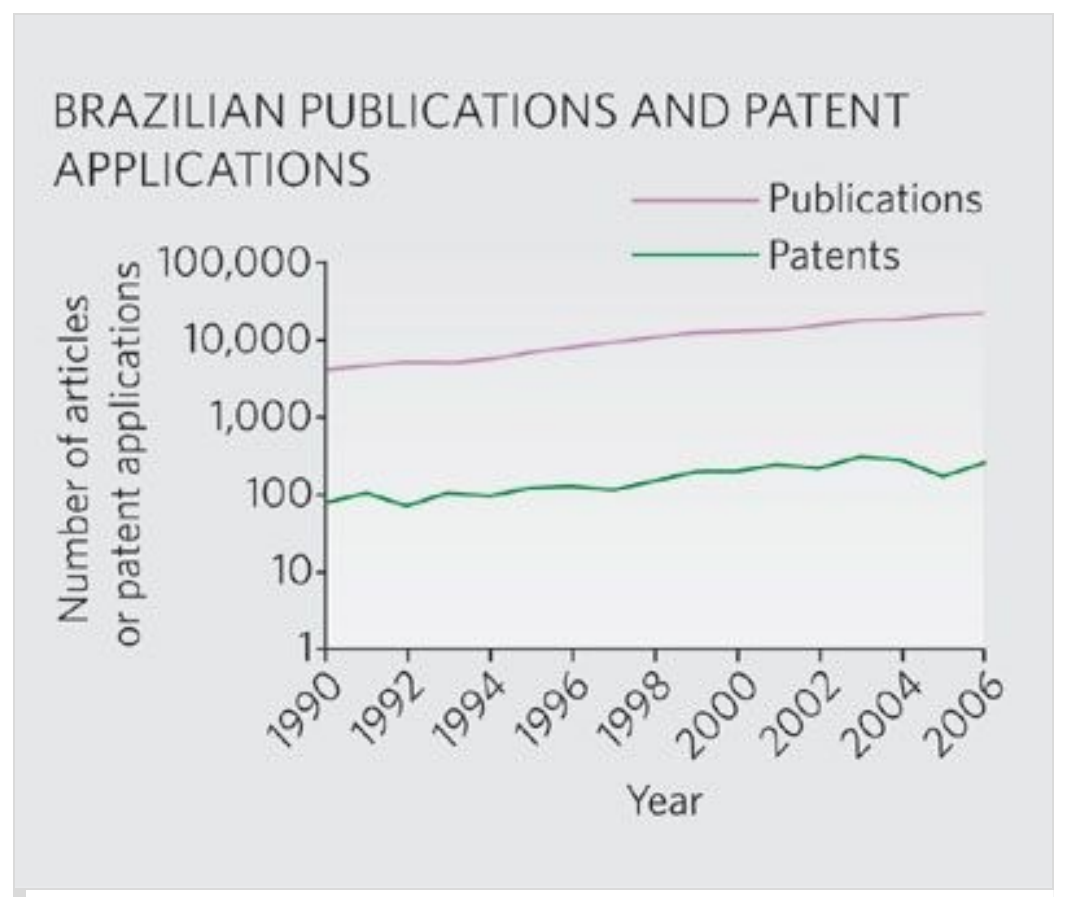

Image: SOURCES: THOMSON SCIENTIFIC/USPTO, 2007

\section{Call for robust policies}

Brazil's current policies on science and technology originated in the 1950s with the creation of two government agencies: one for carrying out research, CNPq (initially called the National Research Council, and now known as the National Council for Scientific and Technological Development); and one for training people, CAPES (Coordination for the Training of Human Resources at the University Level). This 
strategy was inspired by the linear concept of technological development that was prevalent after the Second World War, when the idea of research and development as two distinct activities was born. Basic research was considered to be necessary and sufficient for technological, social and economic improvement. This paradigm had proved useful in developed countries with a strong industrial infrastructure. But in Brazil it culminated in poor communication between academia and industry. As a result, Brazil's industrial policies failed to take into account a growing requirement for more scientific investigation and innovation. This failure also contributed to shaping what has been called a 'passive national learning system' by Eduardo Viotti ${ }^{8}$. This type of system is typical of countries that do not innovate themselves but rely mainly on copying or adapting innovations from elsewhere.

In the absence of long-term, innovation-based industrial policies, successive governments relied on isolated programmes and projects, scattered initiatives, and self-promoting funding agencies to stimulate manufacturing capability in selected areas. Ventures such as the National Immunization Program and the National SelfSufficiency Program in Immunobiologicals allowed Brazil to become a world leader in terms of immunization strategies and campaigns ${ }^{9,10,11}$, but such success could not be forged in other areas as a result of an overall lack of growth in biotechnology. In this way, Brazil has lagged behind other recently industrialized nations, including South Korea and Singapore.

\section{Redressing the imbalance}

Moreover, beginning in the 1990s, the Brazilian government adopted policies that introduced further difficulties for local industrial enterprises. For example, Brazil signed up to TRIPS, the international agreement on intellectual-property rules brokered by the World Trade Organization. This agreement permitted a transition period for developing countries, to allow them to adapt to the new legal framework. However, the Brazilian government did not take advantage of this concession, and Brazil's Industrial Property Law quickly became fully compliant with the agreement, in 1996. As a result, several Brazilian biotechnology and pharmaceutical companies - 
unprepared for the international competition that resulted - did not survive ${ }^{12}$. Today, the outcome of this policy is an annual deficit of US\$2 billion in the trade balance for pharmaceutical products (see graphic) and more than US\$3 billion for all medical products $^{13}$.

Brazil's substandard educational system and socioeconomic imbalance have also contributed to the generally unfavourable climate for innovation. And this lack of innovation, in turn, has prevented these social problems from being rectified.

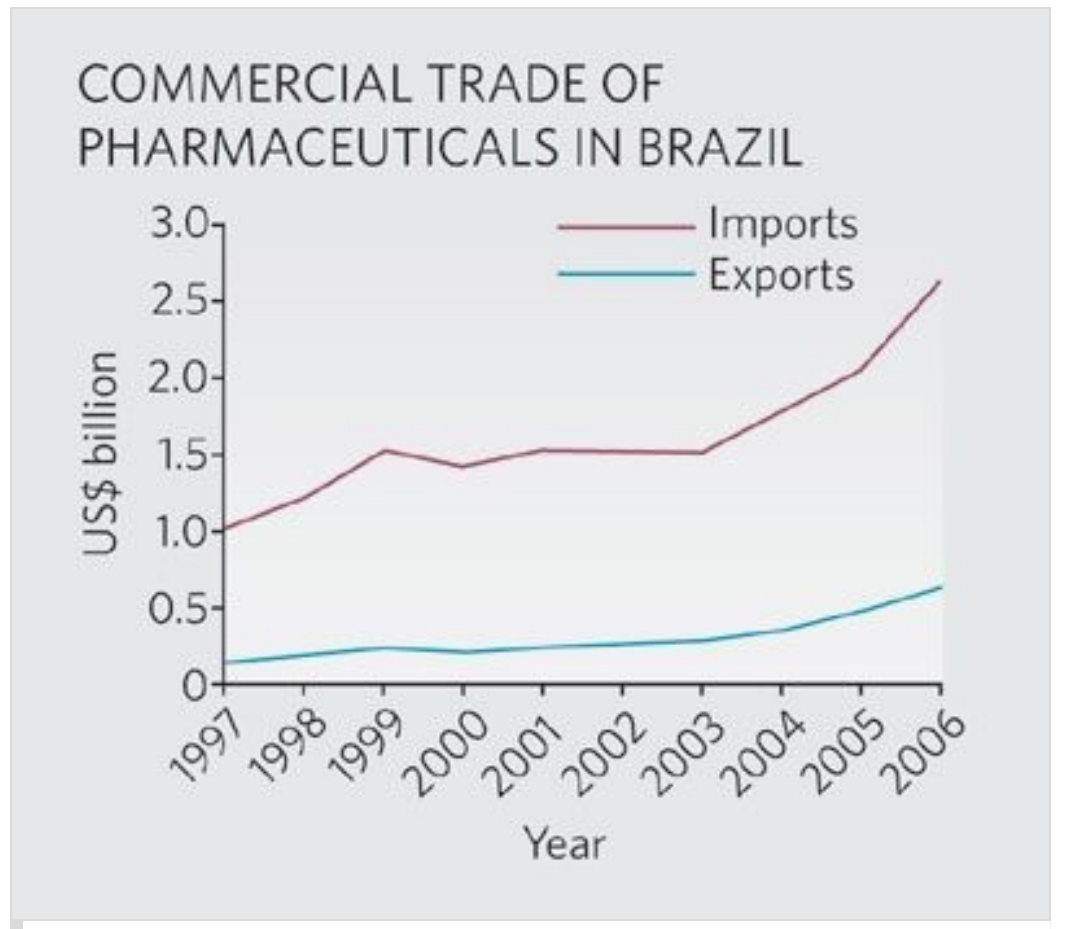

Image: SOURCES: MDIC, BRAZIL/FEBRAFARMA, 2007

But there have been success stories. In the public sector, institutes such as the Oswaldo Cruz Foundation (Fiocruz), in Rio de Janeiro, and the Butantan Institute, in São Paulo, have become well-established producers of immunobiologicals and pharmaceuticals, meeting the requirements of Brazil's Ministry of Health. In addition, the number of graduates and graduate programmes in disciplines relevant to the pharmaceutical industry, particularly chemistry, is increasing ${ }^{14}$. And, in the private sector, companies such as Aché Laboratories, Cristália and Nortec Química are developing and launching new drugs, and manufacturing synthetic components of pharmaceuticals. 
Given all of these factors, it became clear that the way in which research, development and innovation were being carried out needed to change and that these activities had to be coordinated at the national level, within a robust industrial-policy framework.

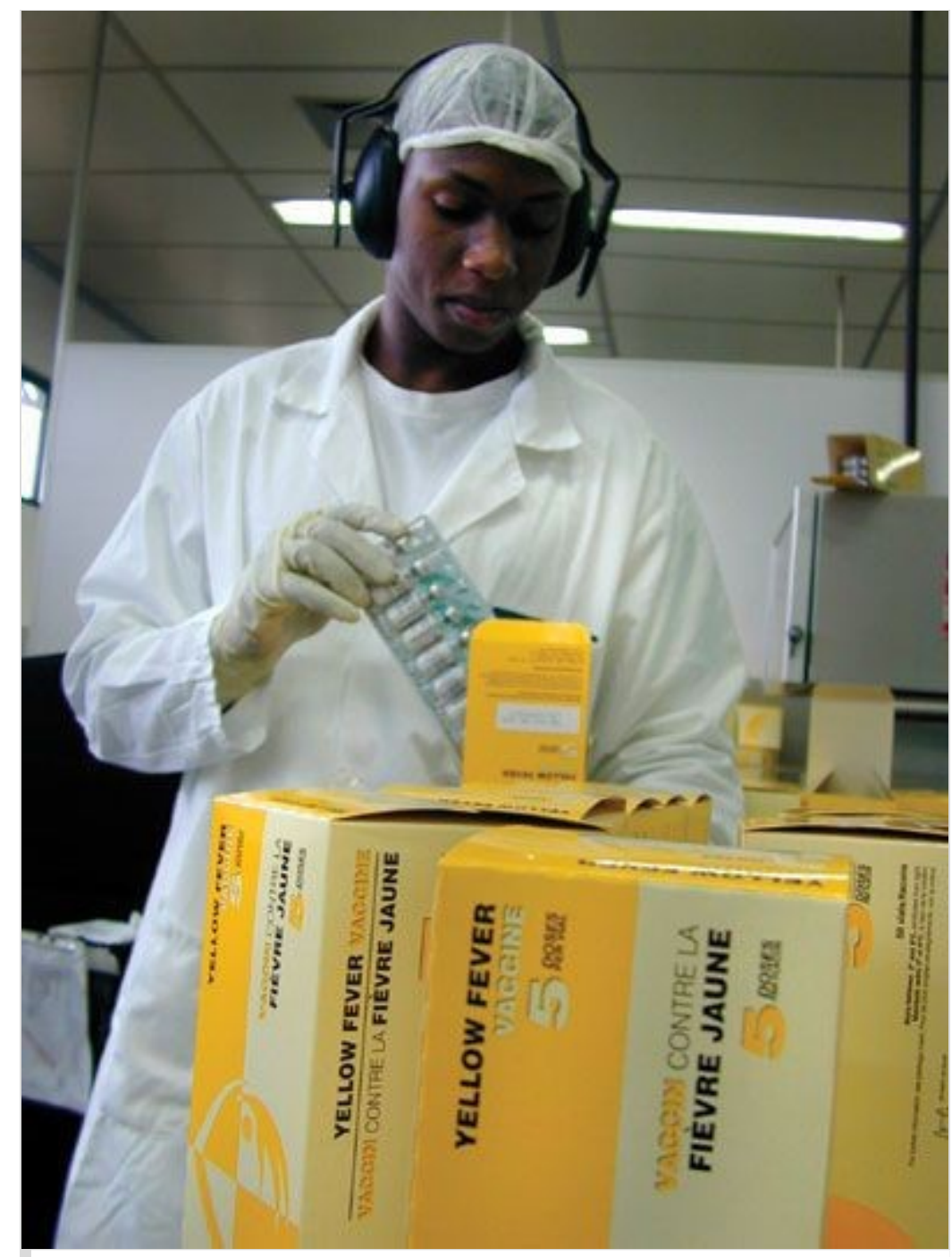

Success story: Brazil is the world's largest producer of vaccine against yellow fever. Image: CCS/FIOCRUZ

\section{Shaping the future}

Recently, Brazil started to lay the foundations for better public health. In 2004, the government approved a new legal and regulatory framework, which includes the Industrial, Technological and Foreign Trade Policy (PITCE). This development initiative links diverse support programmes (financial, technological, logistical, commercial and industrial) with the aim of encouraging innovation. Following on from this, in 2005, 
Brazil introduced the Law of Innovation, which is organized around academic, technological and commercial axes. This law is designed to foster strategic partnerships among universities, technological institutes and businesses, creating a three-pronged approach to innovation.

In addition, a Biotechnology Development Policy was developed this year, providing a broad, structured industrial policy with long-term goals involving the public and private sectors. The policy wisely spreads responsibility across several branches of the government, unlike the earlier isolated and disparate initiatives.

The recent policy and legal changes should help to generate new drugs to treat neglected diseases, by bridging the gap between basic research and drug development. For example, the Department of Science and Technology, which was created as part of Brazil's Ministry of Health in 2000, joined forces in 2006 with the Ministry of Science and Technology (through CNPq) to tackle six neglected and most-neglected diseases: dengue fever, Chagas' disease, leprosy, malaria, tuberculosis and the various forms of leishmaniasis. Together, they have invested US\$10 million in 76 peer-reviewed projects, as part of a pilot research-and-development programme in 2007-08. The programme builds on existing international networks in which scientists actively collaborate in the study of neglected diseases (see 'Collaborative research networks'). And it aims to strengthen capacity for research on neglected diseases, particularly in regions of Brazil where these diseases are endemic. 


\section{Figure 1: Collaborative Research Networks}

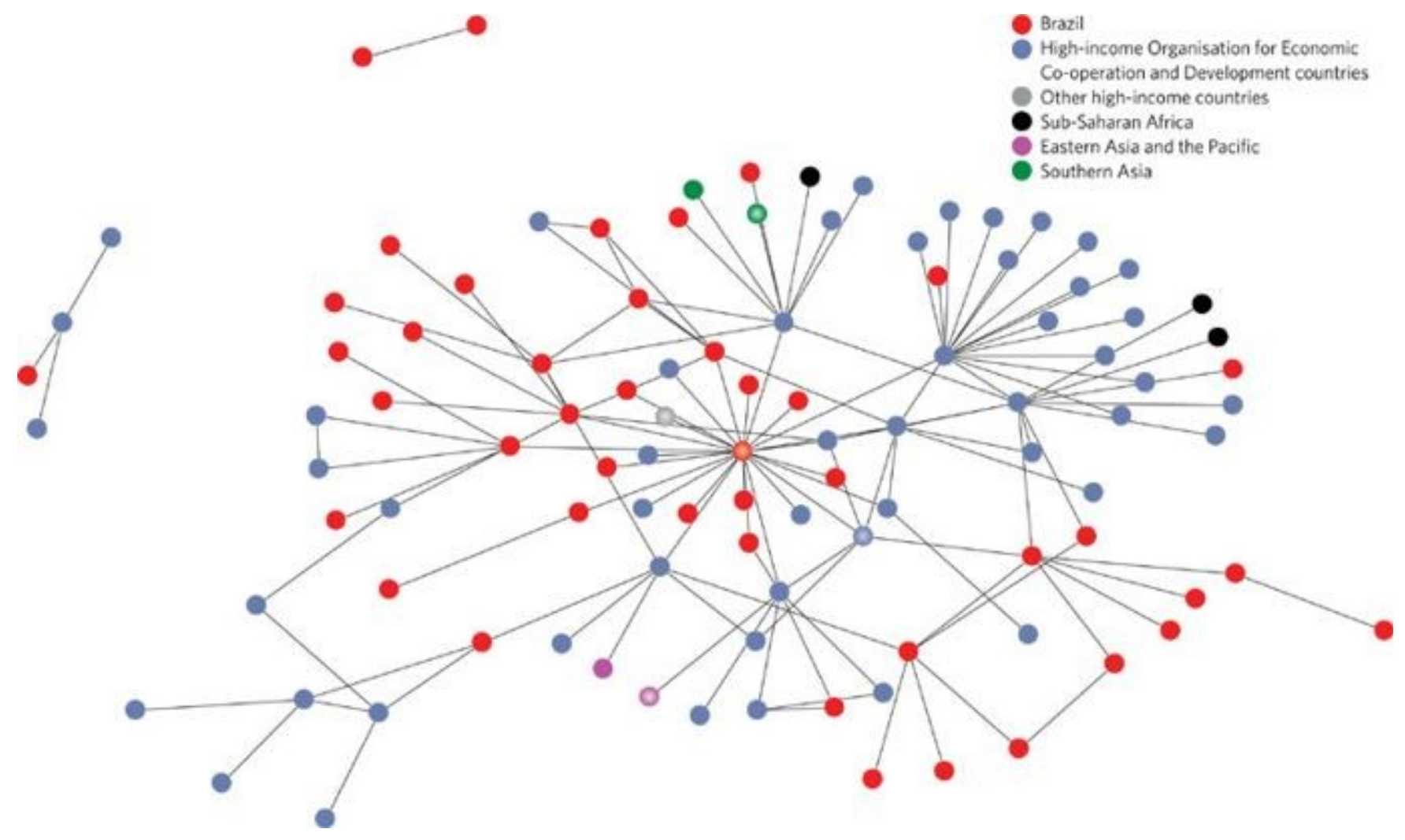

In addition to formal initiatives to promote collaboration, there are already less formal networks between Brazilian researchers and their colleagues worldwide. These networks help to accelerate the progress of research and development, through the sharing of ideas and resources ${ }^{15}$.

Here, we focus on research into a single neglected disease to illustrate the diversity of existing networks. The graphic represents the network of institutes that connects Brazilian scientists studying leprosy with other scientists around the world. The network was generated by extracting author affiliations from articles about leprosy that were published by Brazilians between 2001 and 2005, according to Thomson Scientific. And the position of each institute in the network was determined using the social-networking software UCINET ${ }^{16}$. Each circle represents a particular institute, and each line represents at least one collaboration between these institutes, defined as co-authorship on a scientific article. Institutes are colour coded according to geographical and economic categories designated by the World Bank. It should be noted that red indicates Latin America and the Caribbean, but in this example, all of the institutes in this category are Brazilian.

It is clear from this example that Brazilian researchers are an integral part of a broad international research network that involves both developed and developing countries. It is also evident that Brazilian institutes can have central roles in collaborative research networks that investigate neglected diseases.

\section{C.M.M.}




\section{A move towards manufacturing}

Moving from research on neglected diseases to the development and manufacture of products that prevent, treat and control them will not be an easy task for Brazil. Areas that traditionally have required little technology
"There is an urgent need to devise mechanisms, strategies and policies that address key factors affecting the health of the population." (such as vaccine development), giving the public sector an advantage, are being overtaken by technologically intensive and expensive production processes. So there is an urgent need to devise new mechanisms, strategies and policies, within the framework of PITCE, that address key factors affecting the general health of the population ${ }^{6,7}$.

These strategies should include the deployment of public-sector funds to support public and private manufacturers of treatments for neglected diseases, as well as agencies that manage intellectual-property rights and oversee health regulations.

There are several private initiatives in Brazil that stimulate collaboration between academia and industry on neglected diseases. In addition, since the late 1990s, several global public-private partnerships have been set up to develop drugs, vaccines and diagnostics for neglected diseases (see pages 164 and 166). These include the Malaria Vaccine Initiative, the Drugs for Neglected Diseases Initiative and the Foundation for Innovative New Diagnostics. Brazil should be a welcome contributor to such partnerships, whose rewards could markedly enhance the pharmaceutical production on which the health of Brazil's people depends.

A welcome move in this direction was made this year. Fiocruz and its Centre for Technological Development in Health signed a collaborative agreement with the biotechnology company Genzyme, through its Humanitarian Assistance for Neglected Disease project, to work on the research and development of drugs for 17 neglected diseases. Such strengthening of international collaborations and public-private partnerships, as well as improvements in industrial and educational policies, is crucial 
for Brazil to forge an effective national innovation system and continue on the road to recovery.

\section{References}

1. Levi, G. C. \& Vitoria, M. A. AIDS 16, 2373-2383 (2002).

2. Ferrer, M., Thorsteinsdottir, H., Quach, U., Singer, P. A. \& Daar, A. S. Nature Biotechnol. 22, DC8-DC12 (2004).

3. Olive, J. M., Risi, J. B. \& de Quadros, C. A. J. Infect. Dis. 175, S189-S193 (1997).

4. Almeida, C. [in Spanish with English abstract] Cad. Saúde Pública 18, 905-925 (2002).

5. Bernardes, A. T. \& da Motta e Albuquerque, E. Res. Pol. 32, 865-885 (2003).

6. Morel, C. et al. Innov. Strategy Today 1, 1-15 (2005).

7. Mahoney, R. T., Krattiger, A., Clemens, J. \& Curtiss, R. Vaccine 25, 4003-4011 (2007).

8. Viotti, E. B. Technol. Forecast. Soc. 69, 653-680 (2002).

9. Temporão, J. G. [in Portuguese with English abstract] Hist. Cienc. Saúde Manguinhos 10, 601-617 (2003).

10. Gadelha, C. \& Azevedo, N. [in Portuguese with English abstract] Hist. Cienc. Saúde Manguinhos 10, 697-724 (2003).

11. Buss, P. M., Temporão, J. G. \& Carvalheiro, J. R. Vacinas, Soros e Imunizações no Brasil [in Portuguese] (Editora Fiocruz, Rio de Janeiro, 2005). 
12. Basu, P. Nature Biotechnol. 23, 13-15 (2005).

13. Gadelha, C. A. G. [in Portuguese with English abstract] Rev. Saúde Pública 40, 11-23 (2006).

14. Gama, A. A. S., Cadore, S. \& Ferreira, V. F. [in Portuguese with English abstract] Quím. Nova 26, 618-624 (2003).

15. Morel, C. M. et al. Science 309, 401-404 (2005).

16. Borgatti, S. P., Everett, M. G. \& Freeman, L. C. UCINET 6.0 Version 1.00 (Analytic Technologies, Natick, 1999).

\section{Author information}

\section{Affiliations}

Carlos M. Morel is director of the Centre for Technological Development in Health, Fiocruz, Rio de Janeiro, Brazil.

Carlos M. Morel

José R. Carvalheiro is vice-president for research and development at Fiocruz. José R. Carvalheiro

Carmen N. P. Romero is a science and technology analyst on the Innovation Project at Fiocruz.

Carmen N. P. Romero

Eduardo A. Costa is director of the Medicines and Drugs Technology Institute, Fiocruz. Eduardo A. Costa

Paulo M. Buss is the president of Fiocruz.

Paulo M. Buss 


\section{Rights and permissions}

To obtain permission to re-use content from this article visit RightsLink.

\section{About this article}

\section{Publication history}

Published

12 September 2007

\section{DOI}

https://doi.org/10.1038/449180a

\section{Share this article}

Anyone you share the following link with will be able to read this content:

Get shareable link

\section{Further reading}

Network analysis to support public health: evolution of collaboration among leishmaniasis researchers - https://doi.org/10.1007/s11192-017-2346-6

Ricardo B. Sampaio, Bruna P. F. Fonseca [...] Boleslaw K. Szymanski

Scientometrics (2017)

Hopes build that new infrastructure can aid drug discovery - https://doi.org/10.1038

$/ n m 1011-1174 b$

Bernardo Esteves

Nature Medicine (2011) 


\section{Comments}

By submitting a comment you agree to abide by our Terms and Community Guidelines. If you find something abusive or that does not comply with our terms or guidelines please flag it as inappropriate.

Nature ISSN 1476-4687 (online)

natureresearch

About us

Press

Press office

Contact us

†

releases 